\title{
De la reflexión ideológica a la realidad pedagógica
}

\author{
Cristián D. Expósito ${ }^{1 \mathrm{a}}$ \\ Universidad Nacional de Cuyo, Argentina ${ }^{1}$ \\ Orcid ID: http://orcid.org/0000-0002-5314-97521
}

Recibido: 06 de julio de 2017

Aceptado: 01 de noviembre de 2018

\section{Resumen}

No es posible hablar de educación sin valores, como tampoco es posible hablar de cultura sin ideología. De la misma manera que los valores modelan y le dan sentido a la educación, las ideologías van dando forma a la cultura de los pueblos. Los valores son los responsables de las acciones de las personas, instituciones y sociedades, sin embargo, en base a las ideologías, éstos se ordenan. Es la ideología la que permite unir el entorno de la persona con su propia identidad, es el puente entre lo macro social y lo micro social; un concepto inconmensurable compuesto de valores personales, creencias y determinadas maneras de pensar que brindan una explicación del mundo en que vivimos. Los sistemas educativos de los países están reglamentados por una serie de principios axiológicos que responden a un modelo ideológico preponderante a nivel social. El peligro de estos modelos ideológicos subyace en el reduccionismo que puede llegar a sumir a una comunidad en algo menos que el oscurantismo. En este trabajo se explica la relación existente entre ideologías, valores, cultura y educación partiendo de las conceptualizaciones de las tres ideologías más influyentes en la educación latinoamericana: el cristianismo, el marxismo y el anarquismo.

Palabras clave: axiología, valores, educación, ideologías, pedagogía

\footnotetext{
${ }^{\text {a }}$ Correspondencia al autor

E-mail: expositocd@yahoo.com.ar
} 


\title{
From Ideological Reflection to Pedagogical Reality
}

\begin{abstract}
It is not possible to speak of education without values, nor is it possible to speak of culture without ideology. In the same way that values shape and give meaning to education, ideologies shape cultures. Values are responsible for the actions of people, institutions and societies, however, these are ordered based on ideologies. It is ideology that unites the environment of the person with his own identity, it is the bridge between the social macro and the social micro; an immeasurable concept composed of personal values, beliefs and certain ways of thinking that provide an explanation of the world in which we live. The educational systems of countries are regulated by a series of axiological principles that respond to a preponderant social model. The danger of these ideological models underlies the reductionism that can plunge a community into something less than obscurantism. In this work the relationship between ideologies, values, culture and education is explained starting from the conceptualizations of the three most influential ideologies in Latin American education: Christianity, Marxism and Anarchism.
\end{abstract}

Key-words: axiology, values, education, ideologies, pedagogy

La distancia cínica es sólo un camino -uno de muchos- para cegarnos al poder estructurante de la fantasía ideológica: aun cuando no tomemos las cosas en serio, aun cuando mantengamos una distancia irónica, aun así, lo hacemos. Slavoj Zizek (1992, p. 61)

\section{Introducción}

Para poder acceder al concepto de ideología, es necesario comprender el juego de interrelaciones que se produce entre los valores que son propios de una determinada sociedad, en base al comportamiento de los individuos que la componen. Es decir, los valores impactan en la vida individual, institucional y social conformando un modelo ideológico (Schwartz, 1990, p. 8).

Si bien, la sociedad modela los valores de sus ciudadanos, son las personas que viven en esa sociedad las que modelan los valores sociales. Por lo tanto, estas dos posiciones sociológicas donde la sociedad determina al individuo y, a su vez, los libres albedríos de las personas determinan a la sociedad, no pueden abordarse por separado, sino que deben estudiarse como parte de un todo mucho más complejo denominado ideología. Es la ideología la que nos permite explicar el intríngulis del cómo y porqué, tanto las creencias, representaciones sociales, valores, actitudes, ideas e imágenes se complementan mediante complejos procesos sociales. (López, 2010, p.156)

Los valores conforman en cada sujeto una amplia red axiológica que se relaciona con los distintos sistemas de valores de aquellas personas que integran su comunidad permitiendo, de esta 
manera, organizar un pensamiento simbólico común denominado ideología. (Ardevol y Muntañola, 2004)

El concepto "ideología” tiene dos acepciones bien definidas en el área de la sociología. La definición más académica versa sobre el estudio científico de las ideas desde una mirada racional naturalista (lejos de estar relacionada con la fe o la autoridad) jerarquizada u organizada mediante un sistema de creencias, valores y modos de ser participados por los miembros de una comunidad. La otra acepción hace referencia al concepto de "Falsa Conciencia" concerniente a una serie de ideas equivocadas en cuanto al papel que desempeñan socialmente. (Thompson, 1991, pp. 31-32)

Por lo tanto, la ideología se nutre de los valores morales explícitos y de la particular cosmovisión de los miembros de la sociedad (Connolly, 1967, p. 53). De esta relación entre valores y percepción del mundo surgen los "ismos" aplicados en los aspectos filosóficos, religiosos, políticos y económicos. Como ejemplo, podemos enunciar los conceptos de pragmatismo, capitalismo, subjetivismo, comunismo, etc. De esta manera, la filosofía de una ideología tratará de explicar determinados sucesos sobresalientes que atraviesa una comunidad, dando sentido a su forma de vida e historia. De igual forma abordará los aspectos políticos, la ideología será la encargada de seleccionar y organizar los propósitos y establecer las prioridades. Por esta razón, el líder político toma decisiones basado en la ideología imperante como sustento para optar por determinadas acciones de Estado en detrimento de otras. Así, las ideologías promueven valores humanos para la consecución del éxito en determinadas causas, como por ejemplo, igualdad de género, derechos sociales, etc.

Este sistema de valores personales, credos y formas de pensamiento que brindan una determinada interpretación del mundo y sus cambios denominado "ideología", en determinadas circunstancias, también promueven la necesidad de un cambio. Estos cambios o crisis están íntimamente relacionados con los mismos valores; cuando se produce un distanciamiento entre la forma de ver al mundo y la concepción ideológica del mundo, surge una crisis que promoverá una evolución de la ideología imperante o una sustitución de la misma, ya que los valores se transmiten, subsisten y mutan mediante las ideologías.

En síntesis, la relación que existe entre ideología y los valores es muy íntima e inseparable. Ambas nociones subsisten la una de la otra y le dan sentido a la sociedad en base a la época que atraviesa. De esta manera, la cultura se transmite generacionalmente con el objeto de promover 
valores de adaptación permitiendo una acumulación de conocimiento generación tras generación. "El potencial de adaptación cultural es una de las soluciones más eficientes generadas por el mecanismo de la selección natural para ampliar el potencial de los organismos vivos" (Connolly, 1967, p. 363). ${ }^{\text {b }}$

\section{Desarrollo}

En base a lo expuesto en la introducción, tanto la familia como la escuela son considerados agentes socializadores encargados de la transmisión de la cultura (Jaramillo, 2011, p. 115) y responsables, en último término, de la consolidación de la idea de hombre para dicha sociedad, basados en un determinado modelo ideológico.

Cada vez que abordamos el concepto de educación hacemos referencia al proceso de perfeccionamiento del individuo que la recibe, abriéndole la posibilidad de recrear y reformular determinados patrones sociales considerados valiosos. Por lo tanto, todo acto educativo implica valores.

Dice Escámez (1983, p. 67) que ese modelo o ideal de hombre valioso al que tiende la educación es deseable en sí. Es decir, lo valioso que hay en ese ideal es lo que lo hace deseable desde una mirada subjetivista. Ahora bien, los valores no se dan aisladamente, sino que existe un compendio de ellos que conforman un modelo de ideas, deseos e intereses personales. A su vez, desde el plano social, el sujeto valora aquellos patrones considerados relevantes por su grupo, lo que le atribuye cierto nivel de pertenencia social. Esta conducta implica algún grado de sometimiento siempre y cuando haya armonía entre los valores compartidos. Sin embargo, cuando el sujeto capta la existencia de disociación entre lo que él considera valioso respecto de lo que su grupo de pertenencia plantea como tal, se produce una escisión y deja de pertenecer. Esta situación también puede darse en una escala superior cuando, en determinado momento, lo que una institución o conjunto de sujetos consideran valioso se opone a lo que socialmente está vigente.

Llevando este análisis a un plano objetivo, los modelos axiológicos están compuestos por un compendio de valores a priori, alejados significativamente de la experiencia sensible. A su vez, la educación considera a estos modelos como valiosos en sí y se dedicará a mostrarle a cada alumno

\footnotetext{
b Texto original: "The potential for cultural adaptation is one of the most efficient solutions generated by the mechanism of natural selection for extending the potential of living organisms" (Connolly, 1967, p. 363).
} 
cuan valiosos, estimables, deseables y asequibles son. Se produce una abrupta separación de la mirada subjetivista, psicologista y empirista que planteamos en el párrafo anterior. Aclara Risieri Frondizi (2001) que el objetivismo axiológico es una “...reacción contra el relativismo implícito en la interpretación subjetivista y la necesidad de hacer pie en un orden moral estable” (p. 107). De esta manera, los valores se convierten en una suerte de principios apriorísticos, con la fuerza de una ley objetiva, inalcanzables por la ciencia racional, con una existencia real, autónoma y objetiva; son un aspecto de la realidad que se le impone al sujeto.

Sea cual fuere la postura valorativa asumida, existe la certeza que todo modelo axiológico tiende a:

- La organización de las actividades y acciones de las personas.

- Justificar con mediante fundamentos teóricos toda acción realizada en un determinado momento; e incluso, aquellas que no sucedieron.

- Manifestarse como ideales utópicos capaz de satisfacer todas las necesidades.

- Modelar una imagen de los que nos rodean y de nosotros mismos también.

Cada modelo axiológico, como principio fundamental de la cultura, será responsable en gran medida de la ideología dominante socialmente. A su vez, también influirá en los modelos pedagógicos de dicha comunidad. La educación está íntimamente ligada a la axiología, a tal punto que será la que defina el sentido de la palabra educación (Gervilla Castillo, 1988, p. 415).

Por lo tanto, todo el planteo educativo se reduce a los planteos axiológicos: si los valores dependen directamente del sujeto, el concepto de educación estará unido a la etimología de la palabra educere que hace referencia a sacar, dar a luz, extraer, etc. Este será un modelo pedagógico desarrollista que fluye desde dentro del sujeto hacia fuera, aquí el docente buscará estimular aquellas potencialidades o capacidades del estudiante de una manera abierta, libre, creativa, autónoma y no directiva.

Por el contrario, si los valores no dependen de lo que el sujeto piense, diga o haga; sino que son y existen como realidades objetivas desligadas del plano natural empírico (Díaz, 2011, p. 4); la palabra educación estará vinculada a la etimología de la palabra educare: guiar, orientar, conducir, etc. referido más bien a un proceso teleológico que parte del exterior del sujeto hacia su interior. Está más bien relacionada a los modelos directivos de transmisión de conocimientos y de contenidos que la persona deberá aprender o integrar. La finalidad es llevarla a la meta "valiosa" 
predeterminada mediante la disciplina, el rigor, la calidad estandarizada, la autoridad y la receptividad. (Gervilla Castillo, 1988, p. 416).

Sin lugar a duda, cada uno de estos modelos axiológicos responde al modelo de hombre que se pretende alcanzar mediante la educación. Este modelo puede estar definido por la ideología dominante de cada sociedad, la cual definirá qué valores son importantes para la preexistencia de la misma ya que si bien, todos los valores valen, no valen lo mismo para todos.

A continuación, analizaremos algunos de los modelos ideológicos de carácter teleológico más importantes en el mundo occidental exponiendo aquellos valores que condicionan tanto al modelo de hombre pretendido, como a la concepción educativa planteada para tal fin.

\subsection{Modelo ideológico cristiano}

Es indiscutible la importancia del cristianismo en el aspecto pedagógico y curricular de la educación occidental, desde el "Sermón de la Montaña” (Mt. 5,1), pasando por los grandes padres de la antigüedad, las escuelas catedralicias de la mano de Alcuino de York, el surgimiento de la universidad en la edad media, grandes pedagogos como San José de Calasanz y los padres Escolapios, los Jesuitas, Salesianos y todas las órdenes que se dedicaron y se dedican en la actualidad a la educación e investigación del aprendizaje. Con una trayectoria de 21 siglos y la ramificación de nuevos movimientos religiosos desprendidos del catolicismo, el cristianismo ha sido un vehículo extraordinario para la transmisión de la historia, la cultura y la educación en todo el hemisferio occidental.

El pensamiento religioso tiene una gran capacidad para influir en la sociedad, a tal punto que condiciona la conducta individual y grupal de sus adeptos; impactando en la política, cultura y desarrollo social de las comunidades (Sierra y Julian, 2013, p. 17).

El modelo de educación cristiana es de carácter teleológico desde el momento en que pretende la perfección humanizadora del hombre en todas sus dimensiones, a través de un conjunto de valores esenciales. El hombre es considerado "el valor" por excelencia. El cristianismo plantea que el hombre, en su integridad, es lo verdaderamente importante y promueve, en los evangelios, una serie de normas y principios (modelo patrón) a seguir para la consecución del fin último, la felicidad plena, ver a Dios. "Ciertamente todos nosotros queremos vivir felices, y en el género humano no hay nadie que no dé su asentimiento a esta proposición incluso antes de que sea 
plenamente enunciada" (San Agustín, De Moribus Ecclesiae Catholicae, 1, 3, 4. cit. en Catecismo de la Iglesia Católica, 1993, p. 1718).

El thelos propuesto por el cristianismo católico está fundamentado en los valores planteados en las escrituras y ratificado por cada una de las diferentes iglesias cristianas del mundo, de los cuales el más importante y trascendente es el amor. Mediante este valor el hombre se define como seguidor de Cristo y modela su forma de ser a semejanza de las enseñanzas de su Maestro.

El proceso educativo, basado en el principio del amor, tiene por meta buscar, descubrir y conocer la verdad. Entiéndase por verdad todo aquello que es descubierto por la ciencia racional y todo lo revelado por Dios a través de la fe y la doctrina de la Iglesia. La verdad es el principio fundamental de la libertad, otro de los grandes valores defendidos por el cristianismo. "Decía, pues, Jesús a los judíos que habían creído en él: "Si os mantenéis en mi Palabra, seréis verdaderamente mis discípulos, y conoceréis la verdad y la verdad os hará libres” (Jn. 8,31-32).

Desde la libertad es posible la vida en paz con los demás, no de manera impositiva ni autoritaria, sino a través de la verdad incuestionable. Es por esta razón que en la libertad se encuentra la dignidad del hombre. La dignidad procede o se puede conquistar a través de la educación, medio por el cual el hombre puede acceder a la verdad.

En este pequeño compendio jerárquico de valores planteados por el cristianismo también entran en juego la pureza, humildad y sacrificio puestos de manifiesto de manera magistral por Cristo en la Cruz.

Los valores cristianos son mejor conocidos como virtudes de carácter profundamente personal y trascendentes respecto de los valores objetivos, subjetivos y sociales que venimos analizando.

En tal sentido al referirnos al humanismo integral podemos estar haciendo alusión a todos estos humanismos en la que se encuentra la visión aportada por el cristianismo anterior y posterior al humanismo de la Reforma protestante, en la que continúa vigente la dignidad de la persona humana y sus valores como mensaje del humanismo de Dios. (Solórzano, 2008, p. 349).

La influencia del cristianismo, embebido de la cultura grecorromana, termina por definir el actual modelo de civilización occidental. Nuestra sociedad, vista a la luz de la ideología cristiana, ha ido logrando progresivamente y con el paso de los siglos, un nivel de integración cada vez más humanizado del hombre. 


\section{2. $\quad$ Modelo ideológico marxista}

Para comenzar el abordaje de este tema, es necesario comprender que Marx no concibe un modelo de hombre ficticio, abstracto, fuera de su espacio y de su tiempo. El hombre de Marx es concreto, tal como vivía en la sociedad de su época, condicionado por el crecimiento desmedido de la industria. El hombre es un ser alienado que, por medio de la revolución y el trabajo, entendidos como sociedad y naturaleza, llegará a ser un hombre nuevo o pleno.

En base a este planteo, es congruente que sus tendencias educativas no sean el reflejo de ideas creativas que se pretendan materializar en el niño, sino todo lo contrario. A causa de esto, se critica a la escuela por ser una institución anacrónica que no tiene relación alguna con la realidad. Es una institución alejada de la sociedad viviendo en el "séptimo cielo de sus tradiciones fosilizadas" (Carbonell Sebarroja, 1986, p. 239).

Uno de los valores esenciales que el marxismo pretende potenciar a través de la educación es la praxis, definida como la actividad voluntaria del hombre que intenta transformar la realidad oponiéndose a la teoría (Villalibre, 2011, p. 37).

Krupskaia (1978), uno de los pedagogos soviéticos más importantes del régimen comunista de la antigua U.R.S.S., en el marco de la Escuela Única del Trabajo sostiene que: "Los talleres pretenden ejecutar brillantemente un trabajo; y no se trata del aprendizaje de un oficio concreto sino de la formación para el conocimiento teórico fundamental en la praxis" (op. cit. en Carbonell Sebarroja, 1986, p. 246).

El concepto de praxis en Marx es lo contrapuesto a la teoría, a su vez, implica que la teoría debe reflexionar sobre la praxis. Este modelo filosófico marxista, a diferencia del modelo hegeliano, busca un asidero concreto que se realice en vida del individuo concreto y consciente. De esta manera llega Marx a una praxis como sinónimo de emancipación, trabajo y revolución (Villalibre, 2011, p. 37).

En la teoría marxista, el trabajo es un valor mediante el cual el hombre se humaniza, autorrealiza y modifica su forma de ser y a la sociedad donde vive. Por esta razón, la educación gira en torno a la enseñanza y al trabajo productivo, convirtiendo a la escuela en un sistema de producción.

Esta idea también se encuentra en Simón Rodríguez, el venezolano mentor de Bolívar y uno de los primeros educadores netamente latinoamericano, que realiza un planteo similar en el cual sostiene que la escuela debe estar vinculada con la producción. La escuela es un lugar donde 
se transmite el conocimiento y es, a la vez, un taller para el trabajo y la creación. Él sostiene que lo importante no es la enseñanza, sino la educación. Una escuela debía ser un taller donde se educara a "un hombre distinto, con otra capacidad de pensar y otra posibilidad de hacer" (Puiggrós, 1983, pp. 18-19).

Volviendo al planteo marxista respecto del trabajo en la pedagogía, Lenin reclama, en el VIII Congreso del Partido Bolchevique, la necesidad de una escuela politécnica: “...que dé a conocer, en la teoría y en la práctica, las principales ramas de la producción y que esté basada en la estrecha ligazón de unión de la enseñanza con el trabajo productivo de los chicos" (Lenin cit. en Carbonell Sebarroja, 1986, p. 245).

La idea es que la formación intelectual sea sustituida por la pedagogía del trabajo productivo y práctico como medio para el logro de la instrucción y la educación. Se busca una educación polivalente que permita un desarrollo completo del hombre, proporcionándole los conocimientos científicos necesarios para manejarse en la realidad en la que vive.

Para el marxismo, el concepto de praxis está íntimamente relacionado con la idea de revolución social, como proceso enfocado a derrocar a los sistemas capitalistas que impiden un desarrollo del hombre y de una sociedad humanizadora. En este sentido, la escuela juega un papel importante acelerando el desarrollo y el cambio en las personas.

En palabras de Rodulfo Humberto Pérez Hernández, ilustramos la idea precedente: "Necesitamos que la escuela y la universidad se orienten a preservar estas formas culturales y los valores que encierran y que los difundan. Una pedagogía que explique y oriente que la sociedad capitalista solo se democratiza con revolución socialista” (Pérez, 2010 p. 278).

Otro de los valores que forman parte de este modelo ideológico marxista es la libertad. El marxismo, a través de la educación, pretende la formación de un hombre libre y la libertad está entendida como una toma de conciencia de que el capitalismo es esclavizante. Si el hombre se esfuerza en su trabajo y en el dominio de la naturaleza, conquistará su propia obra creadora y su libertad.

Karl Marx entendía la libertad como el control total sobre las fuerzas alienadas del hombre. La libertad en esta concepción tiene dos aspectos: primero, ser capaz de dominar la naturaleza, a través del desarrollo de las fuerzas productivas, y segundo, la eliminación del poder de fuerzas sociales alienadas. De este modo, es el hombre quien controla. El hombre 
el único actor y autor de la historia. La libertad determina el propio destino; Libertad es autodeterminación (Walicki, 1988, p. 219).

Como ser social, el hombre vive rodeado de sus iguales con quienes se relaciona, para ello debe predominar el valor de la solidaridad, una concepción colectiva de la familia, el hogar, la propiedad, la lucha, etc. "El hogar es la principal encarnación viva de la «libertad e independencia» del trabajador respecto al Capital” (Enguita y Apple, 1986, p. 106).

La jerarquía de valores plasmada por la ideología marxista delimita claramente las tareas de cada miembro del hogar. Obviamente, no debe ser analizado a través de los derechos adquiridos en una sociedad democrática (y aburguesada) del siglo XXI, sino con esa concepción solidaria y colectiva de la familia primitiva.

Cada uno es el amo en su dominio: el hombre en la selva, la mujer en la casa. Cada uno es el propietario de los instrumentos que elabora y usa: el hombre de sus armas, de sus pertrechos de caza y pesca; la mujer, de sus trebejos caseros. La economía doméstica es comunista, común para varias y a menudo para muchas familias (Engels, 1963, p. 91).

Uno de los antivalores marxistas es la religión, generadora de la alienación humana. El hombre crea a Dios porque se siente débil, sometido y desvalido frente a todo aquello que no comprende.

La angustia religiosa es al mismo tiempo la expresión del dolor real y la protesta contra él. La religión es el suspiro de la criatura oprimida, el corazón de un mundo descorazonado, tal como lo es el espíritu de una situación sin espíritu. Es el opio del pueblo (Marx, cit. en Löwy, 2006, p. 283).

Cuando el conocimiento positivo muestra, devela su naturaleza, la religión pierde relevancia y comienza a no tener sentido su existencia. Con la razón y el descubrimiento de la naturaleza, se abre paso a la epistemología sociológica que tiene métodos muy diferentes a los de la religión. Sin embargo, sus objetivos son similares, ya que ambas, pretenden proporcionar modos de comportamiento y orientaciones específicas para la acción (Durkheim, 1972, pp. 130-131).

Lo que se pretende con la ciencia es en definitiva obtener a posteriori lo que la religión proclama a priori: “encarrilar ventajosamente la conducta humana” (Durkheim, 1975, p. 134).

En este sentido, los niveles o fuentes de alienación son los siguientes:

- La Iglesia Católica, ya que sus prácticas no son liberadoras ni progresistas.

- El cristianismo, al estar más cerca de la burguesía que del pueblo.

- Cualquier religión, ya que, por lo general, son inhibidoras de la acción. 


\subsection{Modelo ideológico anárquico}

Comúnmente, el concepto de anarquía se lo identifica con situaciones negativas, descontrol, caos, violencia, ruptura, desorden, etc. Sin embargo, eminencias como Mahatma Gandhi, León Tolstoi y Mijaíl Bakunin, entre otros, coincidieron en esta filosofía, sosteniendo el amor de la libertad y rechazando todo tipo de violencia.

¡Entendernos! He aquí el problema. Todo depende de entendernos. ¿No habrían evolucionado más los pueblos si se entendieran? ¿No habrían dado otro resultado, cierto momento de una parte de esta pobre humanidad en pro de un ideal? Cierto es, que hoy sería algo mañana. Una humanidad que se entendiera, no podría tolerar las tramas e injusticias que soporta la actual (Albamonte, 1913, p. 18).

El anarquismo tiene por objeto la consecución de un hombre nuevo cuya plenitud se logra a través de la solidaridad, el saber científico y la autonomía; frente a la opresión, la explotación, el Estado y el liberalismo, que son tachados como antivalores por esta corriente de pensamiento.

... las exigencias del Estado eran incompatibles con la libertad pues no representa derechos sino privilegios de los que lo constituyen y lo sostienen: los parásitos del poder y del capital. No ofrece libertades al individuo sino a cambio de triple número de servidumbres y sometimientos (...) Mediante la legislación el Estado creaba una normativa legalizadora de su acción, conformando una de sus herramientas fundamentales de dominación en tanto todo el funcionamiento de la sociedad se hallaba íntimamente vinculado a la legislación (Suriano, 2001, p. 259).

Bajo el concepto de libertad se desarrollaron dos corrientes pedagógicas anarquistas, ambas con tendencias muy diferentes:

\section{A. Teorías antiautoritarias, autogestionarias y libertarias}

Partiendo de la base que la mayoría de los pedagogos anarquistas se oponen a la institución escolar como tal y, si bien, algunos de ellos crearon escuelas, lo hicieron con el ánimo de liberar a los ciudadanos de todo prejuicio y dogmatismo (Brenes \& Porras, 1997, p. 134).

Los principales representantes de esta corriente son Tolstoi y Ferrer Guardia, defensores de la espontaneidad del educando.

Las características más importantes de este modelo según Brenes y Porras (1997, pp. 134135) son las siguientes:

- Educación liberadora en el sentido de que desarrolle con plena libertad las potencialidades y auténticos intereses del individuo. 
- Educación autogestionaria: lo que supone la gestión directa de la educación por los implicados en ella. Esto trae consigo el devolver el libre proceso de aprendizaje a las comunidades naturales (estructuras vitales en que se desenvuelve el individuo: barrio, centro de trabajo, comuna, que a su vez funcionan gestionariamente en la sociedad libertaria).

- Educación global: que abarque todos los aspectos de la vida, no separe las parcelas de la realidad, ni al educando del ambiente social en que está inmerso.

- Valoración profunda de la solidaridad, el espíritu crítico y la creatividad.

\section{B. Teorías anti-institucionales o anti-escolares}

Estas teorías se basan en un rechazo total de toda institución política. Pretenden eliminar a la escuela como institución debido a que está íntimamente relacionada y ligada al Estado opresor que interviene directa o indirectamente en la educación y las instituciones dedicadas a educar.

Dentro de esta línea se desarrollan dos instancias diferentes, una de ellas representadas por Goodman, Reirner e lllich que están más vinculados a la antropología anarquista, mientas que por la otra están Bourdieu, Passeron, Baudelot y Establet que están más vinculados a una antropología marxista.

Sin embargo, se caracterizan por rechazar a la escuela por ser una institución esencialmente reproductora de las desigualdades sociales al inculcar el sistema de valores del grupo social dominanate. (Brenes \& Porras, 1997, p. 135).

...los anarquistas, creen que la escuela alimenta el mito del progreso de la humanidad y que, para lograr dicho progreso, reprime los deseos de la ciudadanía a fin de someterlos a la realidad de las exigencias industriales. La escolaridad con la educación permanente de la post-escolaridad mantiene a toda la población en estado de dependencia durante la vida entera. (Fullat, 1980, p. 313).

La alternativa propuesta consiste en el libre intercambio de los conocimientos en un ambiente desescolarizante. Rubinsztain, (2013, pp. 4-5) sostiene que, este tipo de planteo también se da en Latinoamérica bajo un ambiente de opresión que permite el surgimiento de nuevos proyectos educativos para aquellas personas excluidas del sistema tradicional, estatal, histórico y cultural. El concepto de educación popular se da fuera del discurso convencional mediante educadores populares, intelectuales de la revolución, cristianos y sacerdotes de base, junto a los movimientos campesinos y estudiantiles. 
Este modelo de educación popular estaba diseñado para llevarse a cabo con adultos en sus propios espacios de trabajo cotidiano, por tal motivo, era inviable hablar de una escolarización convencional. En base a este planteo se dice que Paulo Freire avalaba un modelo desarrollista, de base y anti-escolarizador ya que estas personas no se amoldaban a las exigencias de la educación estatal. (Michi, 2011, p. 10).

Cabe destacar que ambas teorías esbozadas abordan el concepto de libertad como tema principal de la ideología anarquista. Este es el valor que le da sentido y fundamenta el ideal de hombre y sociedad. "Principios que ponían énfasis en la libertad del individuo y en la crítica excluyente de la autoridad encarnada por el Estado". (Suriano, 2001, p. 26).

El concepto de Estado era lo más parecido a un monopolio de poder que sometía al hombre por la fuerza. Sólo por el uso de la inteligencia, el hombre podía salir de las tinieblas de la ignorancia para oponerse al yugo opresor del estado desde la razón. "En este sentido, ciencia y razón se convertían en elementos iluminadores y reveladores que guiaban a la humanidad desde la ignorancia al conocimiento; desde la autoridad a la anarquía y desde la reacción a la revolución y la libertad". (Suriano, 2001, p. 43).

El hombre llega a ser libre mediante un proceso de liberación de la explotación económica, la opresión intelectual, social y política. Pero, es necesario tener en cuenta que para los anarquistas la libertad va ligada a otros valores tales como la igualdad, solidaridad y justicia. Estos valores son los promotores de la felicidad en su máxima expresión.

En la base de la concepción anarquista se hallaba fuertemente arraigada la idea de libertad, una libertad que tenía por objeto hacer feliz al individuo, pues era un derecho natural inherente al hombre mismo que no debía ser perturbado por elementos extraños. (Suriano, 2001, p. 78).

Ahora bien, cuando el planteo de la libertad como fin último de la ideología anarquista cobra una relevancia que trasciende los medios para conseguirla, este modelo se convierte en algo de carácter más bien reduccionista. Si el concepto de revolución es planteado como una transformación radical en la forma de vida del hombre, a tal punto, que muchas veces "se justifica" recurrir a la violencia para alcanzarlo, para ser libres.

\author{
"LOOR A LOS MÁRTIRES DE LA COMMUNA \\ ODIO ETERNO A SUS VERDUGOS \\ Proletarios de todos los países, acordaos. \\ Aprestaos a la venganza y haced que la tea \\ regeneradora abrace todo lo que a su paso \\ encuentra para liberar al mundo de tanta fétida miseria.
}




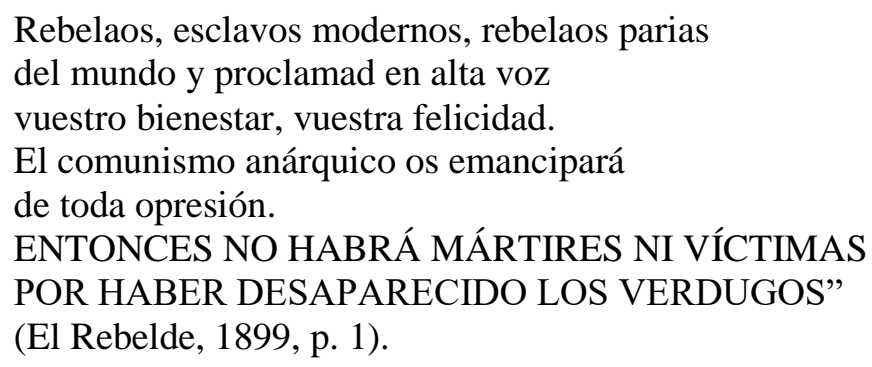

Siguiendo este itinerario de valores recogidos por la anarquía, está también como principal exponente la razón, camino para lograr el conocimiento de la verdad.

En esta reconstrucción de la historia, los combates sociales eran reforzados con el triunfo de la razón y la evolución, siempre progresista, de la ciencia que, en una visión un tanto optimista, debían acompañar a los trabajadores en el proceso liberador y revolucionario (Suriano, 1997, p. 89).

Como sostiene Suriano (1997, p. 89) la razón permite que el trabajo se organice por medio de la autogestión como fuente de alegría y solidaridad.

Los anarquistas no sólo pretendían abrir paso a los conocimientos científicos. Sino que también se buscaban en los sujetos habilidades: ya sea de tipo morales y de personalidad. Era muy importante lograr en los individuos la responsabilidad de ser, el autogobierno, el carácter por medio de la construcción de la voluntad de trabajo (Sardu, 2008, p. 196).

Este concepto de autogestión también se extiende hacia las escuelas como comunidades educativas autónomas en sus decisiones. Como explicamos anteriormente, la escuela tal cual está concebida, debe desaparecer debido a que es un ente que se dedica sólo a la reproducción de patrones existentes en la sociedad, totalmente enfrentados con el pensamiento anarquista.

Durante el día este salón se convierte en sala de estudio, taller de planchado y labores o clase de dibujo. (...) Esta es la sala de geografía esa la de historia, aquella la de ciencias naturales, la de más allá un laboratorio en construcción de física y química (...) Un sistema de educación completa, seria aquel que formarse individualidades originales y robustas, capaces de contrarrestar las fuerzas anuladoras del ambiente y bastarse en todo momento así mismo. Formar el carácter (...) La voluntad es la piedra angular del carácter y también de la dignidad personal de los hombres. Sin el ámbito del trabajo que estimula nuestra voluntad diariamente, hasta el genio fracasa (Barcos, 1913, pp. 78).

\section{Conclusión}

Los valores son los responsables de las acciones de las personas, instituciones y sociedades, sin embargo, estos se ordenan en base a las ideologías subyacentes. Es la ideología la que permite unir el entorno de la persona con su propia identidad, es el puente entre lo macro social y lo micro social; un concepto inconmensurable compuesto de valores personales, creencias y determinadas 
maneras de pensar que brindan una explicación del mundo en que vivimos. Es la ideología la que promueve, modifica y mantiene determinados valores sociales (López, 2010, p. 168).

El modelo axiológico de todo sistema educativo está sustentado por alguna estructura ideológica. El problema está en caer en una especie de fanatismo y sumir a una comunidad en algo menos que el oscurantismo. Las tres ideologías analizadas han demostrado, a través de la historia, que sus principios pueden ser tergiversados generando, de esta manera, un reduccionismo de la realidad. Por tal razón es necesario que los países, al momento de diseñar sus políticas educativas, no caigan en estos vicios y puedan generar un marco axiológico consistente donde instituyan las bases para la formación de los hombres del futuro. Esto reviste gran importancia ya que hoy en día estamos atravesando una crisis de valores que está socavando los principios culturales occidentales que daban un sentido de identidad a los países latinoamericanos, forjando una nueva ideología del cambio y la innovación infinita que sumerge al hombre en el hastío. Esta crisis cuestiona el principio absolutista de la razón, niega la esencia pura del hombre separada de las circunstancias sociales y de una realidad, siempre teñida de interpretaciones culturales subjetivistas (Gervilla Castillo, 1993, p. 52).

Hoy en día los valores han perdido su vigor, cada ciudadano elabora un sistema de valores a su imagen y semejanza forzando a que lo bueno y lo malo dependan exclusivamente de su propia subjetividad egocéntrica. Se hace evidente la máxima de Protágoras que dice que es el hombre la medida de todas las cosas. (Montero, 2014, p. 86).

Se ha vuelto imperioso destapar todos los temas que culturalmente eran considerados tabú y se los han llevado a la palestra educativa perdiéndose de vista lo normal o normado y desestimando aquellos valores que daban sentido e impartían orden y estructura en la sociedad. Una educación sin valores está próxima a la ignorancia y una sociedad sin educación está próxima a la barbarie, como dice Domingo F. Sarmiento (1874) “...porque el saber es riqueza, i un pueblo que vejeta en la ignorancia es pobre i bárbaro..." (p. 239).

Tenemos que volver a centrar la acción educativa y el currículum en el valor como elemento rector de la pedagogía. De esa manera, enriquecemos la cultura de nuestros pueblos y crecemos como individuos y sociedad. "Una ciudadanía que aprende a disfrutar aprendiendo, fomentando la mente abierta a todo conocimiento, pues quien aprende tiene más capacidad y herramientas para 
seguir aprendiendo (...) Todo lo demás (...) vendrá como consecuencia de una sucesión de generaciones educadas bajo los fundamentos de la adquisición cultural.” (Ruíz, 2017, p. 43).

\section{Referencias}

Albamonte, V. (1913). Esperanto. Revista La Escuela Popular, Órgano de la Liga de Educación Racionalista, 1 (10).

Ardevol, E. \& Muntañola, N. (coords.). (2004). Representación y cultura audiovisual en la sociedad contemporánea (Vol. 20). Editorial UOC.

Barcos, J. (1913). Plan de una escuela integral, Conferencia dada en "La Casa Suiza" el 17 de Julio. Revista La Escuela Popular, Órgano de la Liga de Educación Racionalista, (10), Año 1, Buenos Aires

Brenes, E., \& Porras, M. (1997). Teoría de la Educación. Universidad Nacional de Educación a Distancia UNED. España.

Carbonell Sebarroja, J. (1986). Marx y la pedagogía. Cuatro notas sobre la pedagogía marxista y su crítica al reformismo pedagógico y escolar. F. Enguita (comp.), Marxismo y sociología de la educación, Madrid, Akal.

Catecismo de la Iglesia Católica. (1993). Conferencia Episcopal Argentina. Buenos Aires.

Connolly, W. E. (1967). Political science and ideology. Transaction Publishers.

Díaz Mesa, M. C. (2011). Una visión de los valores y su formación en el siglo XXI. Avanzada Científica, 14(2), 12-22.

Durkheim, E. (1972) La educación moral. Schapire, Buenos Aires.

Durkheim, E. (1975) Educación y Sociología. Península, Barcelona.

El Rebelde (18 de marzo de 1899), Buenos Aires.

Engels, F. (1963) [1884 en alemán]. El origen de la familia, la propiedad privada y el estado. Editora Política.

Enguita, M. F., \& Apple, M. W. (1986). Marxismo y sociología de la educación (Vol. 79). Ediciones AKAL.

Escámez Sánchez, J. (1983). Educación y Normatividad. AA.VV. Teoría de la Educación I. El problema de la Educación. Murcia: Límite.

Frondizi, R. (2001). [1972 5º edición]. ¿Qué son los valores? México D.F.: Breviarios del Fondo de Cultura Económica. 
Fullat, O. (1980) Filosofías de la educación, Ceac. Barcelona. 1978. BRAMELD, TH.: Cultural Foundations of Education, Harper and Row. New York. 1957. Trad. Cast: "Bases culturales de la educación”, Eudeba, Buenos Aires. 1961. DIENLT, K.: Antropología Pedagógica. Aguilar. Madrid, 1980.

Gervilla Castillo, E. (1988). Educación y valores. In Filosofía de la educación hoy (pp. 397-426). Dykinson.

Gervilla Castillo, E. (1993). Postmodernidad y educación. Valores y cultura de los jóvenes. Madrid: Dykinson.

Jaramillo, L. (2011). Concepción de infancia. Zona próxima, (8).

Krupskaia, N., (1978). La educación comunista, ed. Nueva Cultura, Madrid.

López, C. (2010). Valores e ideología. CICAG, 1(1), 154-170.

Löwy, M. (2006). Marxismo y religión: ¿opio del pueblo? La teoría marxista hoy. Problemas y perspectivas. CLACSO 281-296

Michi, N. (2011). Educación de adultos, educación popular, escuelas, alternativas. Cinco décadas de encuentros y desencuentros. Finnegan, F.(Comp.). Educación de Jóvenes y Adultos. Políticas, instituciones y prácticas. Buenos Aires: Editorial AIQUE.

Montero, R. (2014). El desafío de la posmodernidad para el cristiano. Apuntes Universitarios. Revista de Investigación, 4(1).

Pérez Hernández, R. H. (2010) Pedagogía para el socialismo científico. Claves teórico conceptuales para una pedagogía desde la clase trabajadora. Diálogo de Saberes 3 (7-8-9), 269-279.

Puiggrós, A. (1983). Discusiones y tendencias en la educación popular latinoamericana. Nueva Antropología, 6(21), 15-40.

Rubinsztain, P. (2013). Educación pública y educación popular. Sentidos históricos y prácticas pedagógicas. In X Jornadas de Sociología. Facultad de Ciencias Sociales, Universidad de Buenos Aires.

Ruíz, D. (2017). Cultura y Discultura, Realidades Contrarias. Conceptos Antagónicos. Av Notas Revista de Investigación Musical, (3).

Santa Biblia (1987). Versión de Monseñor Juan Straubinger. Editorial Gaviota, Barcelona.

Sardu, A. (2008). Una molesta piedra en el camino: Educación Anarquista. Theomai: estudios sobre sociedad, naturaleza y desarrollo, (17), 11.

Sarmiento, D. F. (1874) Facundo ó Civilización i Barbarie. Cuarta Edición en Castellano. Librería Hachette y cia. París 
Schwartz, B. (1990). The creation and destruction of value. American Psychologist, 45(1), 7.

Sierra, C., \& Julian, E. (2013). Representaciones sociales de religión que inciden en el desarrollo humano de los habitantes del centro poblado de Naranjal Timaná-Huila que participan de las denominaciones Católica, Pentecostal y el Movimiento Misionero Mundial. (tesis de licenciatura). Universidad Nacional Abierta y a Distancia.

Solórzano, G. A. (2008). El hombre, un ser integral. Foro de Educación, 6(10), 347-367

Suriano, J. (1997) Banderas, Héroes y Fiestas Proletarias. Ritualidad y Simbología Anarquista a Comienzos del Siglo Boletín del Instituto de Historia Argentina y Americana "Dr. Emilio Ravignani" Tercera serie, núm. $15,1^{\circ}$ semestre

Suriano, J. (2001). Anarquistas: cultura y política libertaria en Buenos Aires, 1890-1910. Ediciones Manantial.

Thompson, E. P., \& Pérez, J. M. (1991). Algunas observaciones sobre clase y falsa conciencia. Historia Social, 27-32.

Villalibre, M. B. (2011). Para una teoría actual sobre la verdad. Naturaleza y gracia: revista cuatrimestral de ciencias eclesiásticas, (3), 491-541.

Walicki, A. (1988). Karl Marx como filósofo de la libertad. Critical Review. A Journal of Books and Ideas, 2(4).

Zizek, S. (1992). El sublime objeto de la ideología. Siglo xxi. 